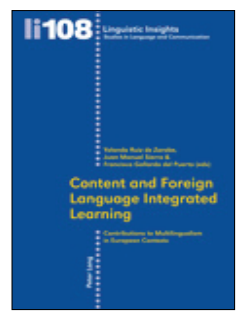

\title{
Content and Foreign Language Integrated Learning
}

\author{
Yolanda Ruiz de Zarobe, Juan Manuel Sierra, \\ Francisco Gallardo del Puerto (eds). \\ Bern: Peter Lang, 2011. 343 pages. ISBN: 978-3-0343- \\ 0074-2.
}

Content and Foreign Language Integrated Learning (CLIL) teachers and researchers are in luck with this new volume published by Peter Lang. They will all find good reasons to justify it is worth working on CLIL projects. The articles inside create an oasis in the middle of the desert, a mirror to look themselves into and see others with the same difficulties but also satisfactory results, and a wide range of ideas for further research and study on the field. As clearly explained by the editors in the introductory chapter "Introduction - Content and Foreign Language Integrated Learning: a Plurilingual Perspective", the book is divided into two parts. The first part, entitled "Research in European Contexts", assembles six chapters that offer an interesting picture of CLIL research studies in Europe. The second part, "Classroom Practice and Outcomes", describes five different classroom experiences and projects on the topic.

In "Approaching the economic, cognitive and health benefits of bilingualism. Fuel for CLIL", Peeter Mehisto and David Marsh detail economic, cognitive and health benefits of bilingualism. These authors provide considerable information which indicates that bilingualism holds substantial economic potential for the individual and for societies at large. They also support that a growing body of research suggests bilinguals have greater executive control, increased multicompetence and learning capacity, enhanced problem-solving skills, and improved memory. On top of those benefits above, bilingualism seems to slow down mental decline as a person ages.

"Post-method pedagogies: Using a second or other language as a learning tool in CLIL settings" by Do COYLE explores the implications of language using and language learning in classrooms where the medium of instruction is not the first language of the learners. The article is divided into two 
sections. In the first section the author considers language as a learning tool and the implications for the theory and the practice. In the second one she reports on classroom research which focuses on practitioner ownership of language using as a learning tool in CLIL settings.

Particularly interesting is the approach by Y.L. TERESA TING in "CLIL and Neuroscience: How are they related?”, in which she discusses some concerns regarding education in the 21 st century and argues that CLIL can provide a learning context which suits 21 st century reality. She grounds this proposal within basic neuroscience research findings.

CARMEN PÉREZ-VIDAL in "Language Acquisition in three different contexts of learning: Formal Instruction, Study Abroad, and Semi-immersion (CLIL)" discusses the impact of CLIL and Study Abroad as central features in the European strategy toward multilingualism on the acquisition of English as a foreign language by learners in Spain, including data from primary, secondary and tertiary education. This chapter is really interesting for researchers as she provides them with rich data to tackle what is currently one of the main areas of interest in second language acquisition research. Particularly rich is the wide range of research analysed to support data from a comparative point of view (pros and cons of the three learning contexts analysed).

"Which language competences benefit from CLIL? An insight into applied linguistics research" by YOLANDA RUIZ DE ZAROBE, offers a review of some of the evidence provided by applied linguistics research in order to analyse which linguistic areas and skills benefit most from CLIL, and which other areas still show weaknesses that should be further addressed.

To close this first section of the book, Teresa NAvÉs in "How promising are the results of integrating content and language for EFL writing and overall EFL proficiency", explores the potential benefits of CLIL instruction on both overall EFL proficiency and EFL writing proficiency.

As mentioned above, the second part of this volume concentrates on classroom practice and outcomes. EMMA DAFOUZ MiLNE starts this part with "English as the medium of instruction in Spanish contexts: A look at teacher discourses", where she offers some insight into multifaceted discourses that CLIL teachers need to address in their respective classrooms.

In "CLIL and project work: Contributions from the classroom", JUAN MANUEL SIERRA presents the characteristics of a comparative project CLIL 
programme carried out at a secondary school in the Basque Autonomous Community. He offers the opinions of students about their learning experience analysed by means of a study conducted after the implementation of the CLIL programme. There are some conclusions and pedagogical implications in order to improve further implementation of CLIL through cooperative project work.

The following chapter, "Analysing the situation of teachers in the Madrid bilingual project after four years of implementation", looks back on the past experience of a project in its fifth year and sees how the English teachers involved feel about its implementation. RAQUEL FERNÁNDEZ and ANA HALBACH found out about teachers' evaluation of the project and some teachers' comments seem to indicate that they have not quite understood bilingual education. The authors conclude that teachers need appropriate methodological and linguistic training and the opportunity to reflect on their thinking.

The authors of "Teaching-learning foreign languages in the Basque State Schools: the INEBI and BHINEBI projects, a practical example for CLIL and competence-based learning", María Luisa García GurrutXaGA, Montse del Nozal, Milagros Villa and Rosa Aliaga present different projects that are being implemented in the Basque Autonomous Community, where English is a third language of instruction in schools. Some projects are related to the English subject itself, and the Plurilingual Experience is a project related to the teaching and learning of any other subject in a foreign language. This group of authors explains the aims, objectives and steps of the projects, and gives some ideas for the future. The project is supported with a lot of training for the teachers involved.

In "Key factors to be considered by CLIL teachers", InMACUlaDA MuÑOA BARREDO, focuses on one of the projects the ikastolas (Basque medium schools) are implementing in order to develop the multilingual school model: a CLIL project called SSLIC (Social Science and Language Integrated Curriculum). It consists of teaching Social Sciences only through English in the last two years of compulsory education (ages 14-16). She underlines some of the key factors that teachers and schools need to consider when implementing CLIL programmes.

Juan Manuel Sierra, Francisco Gallardo del Puerto and Yolanda RUIZ DE ZAROBE close the book with a conclusion chapter entitled "Good practices and future actions in CLIL: Learning and pedagogy". Here they 
synthesize the central issues raised by the different contributors in the volume and suggest the main challenges and future actions for CLIL. The chapter highlights three main branches of further research needed: content mastery, first language learning and acquisition of the foreign language.

In general, the volume offers an excellent library for further references on the topic. The reader will find useful and accurate links within the chapters to other chapters in the book; thus, interrelating topics, findings and research lines. All studies and experiences exude optimism through satisfactory results of applying CLIL in language learning although in all cases there are open doors to further research and improvement. Therefore, with such scenery the book is highly recommended for all teachers and researchers working on CLIL or interested in starting a new experience or project related to this field.

Reviewed by Ana María Saorín Iborra

Universitat Jaume I, Castellón (Spain) saorin@ang.uji.es 